\title{
Neurocognitive Effects of Hypoxia: A Brief Review
}

\author{
Daniel A Jaffe*, Jennifer K Hewit, Joseph M Frullaney and Alexander J Bedard \\ Department of Physical Education, United States Military Academy, USA
}

Submission: July 7, 2018; Published: July 17, 2018

*Corresponding author: Daniel A Jaffe, Department of Physical Education, United States Military Academy, USA, Tel: 845-938-3950;

Email: Daniel.Jaffe@usma.edu

Abbreviations: ImPACT: Immediate Post-Concussion Assessment and Cognitive Test; KD: King Devick test; RER: Respiratory Exchange Ratio; CDQC: Combat Diver Qualification Course

\section{Introduction}

One of the most common ways physicians currently diagnose and assess concussions and concussion recovery is using the Immediate Post-Concussion Assessment and Cognitive Test (ImPACT) [1]. This test is a neurocognitive assessment that provides feedback based on categorical norms. It is plausible that the ImPACT, or other similar neurocognitive tests, could be a tool in measuring the effects of hypoxia on cognitive performance. Hypoxia, defined as a low partial pressure of Oxygen in the blood stream, has many similar symptoms to those noted with concussions, namely a significant decrement in cognitive performance [2].

Repeated neurocognitive assessment is commonly used in order to diagnose concussions based on cognitive function, with the ImPACT test being the most commonly used assessment [1]. This neurocognitive assessment is essential to understanding differences in performance and progress when used during concussion recovery. In a validation investigation of the ImPACT, researchers had 95 college varsity athletes complete baseline cognitive testing approximately 2 years apart [3]. Subjects were concussion-free during the entirety of this investigation. The researchers in the study performed analyses on the gathered data and found that the intraclass correlation causation estimates for visual memory was 65 ; for processing speed it was 74 and for reaction time it was 68 [3]. With regards to verbal memory and symptom scale, there was greater variability at 46 and 43, respectively [3].From these results, the researchers concluded that the cognitive performance of these college athletes remained relatively stable over the evaluated 2 year time period [3]. These results support the notion that baseline neurocognitive testing need not be evaluated annually.

An alternative to using the ImPACT for neurocognitive function assessment is the King Devick (KD) test. Recently, the
KD test has been advocated as an easy way to diagnose and monitor concussion and immediate neurocognitive injury in a field setting e.g., sideline evaluation [4]. Concussions in sport is a very real danger and additional tests like the KD test could enhance the understanding of medical professionals with regards to athlete safety.With the popularity of the ImPACT test on the rise amongst sports medicine professionals, the question has arisen regarding how the KD test would perform in comparison. Dziemianowicz et al.[5]compared test results from the KD to ImPACT composite scores. Unlike with the ImPACT, the KD test relies on visual motor speed analysis for a rapid assessment of cognitive visual processing and performance. Most specifically, the KD test is designed around rapid number naming and pattern identification.

Utilizing 35 recently concussed athletes, researchers sought to validate the KD test as a comparable diagnostic tool to the ImPACT[4]. In the investigation, subjects completed four separate clinical visits where each time they completed a symptom test, the KD test, and the ImPACT[4]. Researchers found that the KD test and the ImPACT test both indicated parallel improvements as symptoms continued to resolve for the patients [4]. Researchers hypothesized that both assessments run in parallel, and are somewhat interchangeable, when using ocular motor speed tracking as the primary mechanism for monitoring recovery [4].With its simplicity of administration, the King Devick (KD) test allows for researchers to emphasize and evaluate the role of impaired eye movement in patients and correlate these findings with sub-optimal brain function [6]. In this investigation, researchers administered the KD test to a group of amateur, adolescent boxers prior to, and immediately following a fight. Utilizing a single-blinded approach, third party test evaluators were given the results of the KD tests for each of the subjects and asked to evaluate the efficacy of the assessment 
for identifying head trauma and symptoms of concussion. Third party evaluators were able to note, with significance, a decline in performance between baseline and post-fight results given the dramatic increase in time to perform KD test, further supporting the efficacy of field-expediency in test administration [6].

While both the ImPACT and KD test have been frequently validated to identify symptoms of concussions, research is relatively limited on the value of these tests in identifying the effects of both chronic and acute hypoxic exposure. Researchers have noted that hypoxia, or reduced arterial Oxygen saturation, can greatly impair human performance [7]. Most often, these symptoms are associated with exposure to altitude as a direct consequence of the reduced partial pressure of atmospheric Oxygen, reducing the gradient of exchange at the level of the alveoli. With exposure to altitude, assessments should be administered on a stepwise basis, as symptoms associated with hypoxia have been shown to increase incrementally due to both increased time of exposure, and increased altitude. Bartholomew et al. [7] recruited 72 subjects and flight instructors in aviation school to participate. Subjected were asked to read and recall a series of numbers at exposure to a variety of simulated altitudes, to include $2,000,12,500$, and 15,000 feet. Subjects were also given either high or low memory load pieces of information to recall over the radio during the evaluation [7].

Researchers found that individuals assigned high memory load tasks demonstrated marked declines in performance with incremental exposure to altitude [7]. These findings imply that altitude, and in effect hypoxia, influences the amount of cognitive resources available for information processing. This decline in cognitive function could greatly increase the risks associated with performance of task-related objectives in certain professions requiring altitude exposure e.g., aviation, military, etc. Researchers suggest that future investigations seek alternative mechanisms for simulating hypoxia via both altitude and exercise to identify the potential compounding effect of physical activity on exacerbating symptoms [7].

Aside from high altitude exposure, hypoxia can also be induced by breath holding while performing physical exertion most commonly observed in swimming and free diving. In both of these sports, hyperventilation is the primary means through which the human body can decrease Carbon Dioxide saturation in the blood, enhancing individual breath hold capacity [8]. A dramatically reduced Carbon Dioxide concentration in the blood carries the risk of increased risk of syncope, or loss of consciousness, which could be fatal in the underwater theater. Lindholm et al [8] recruited 8 trained breath hold divers, half of which had previously experienced hyperventilation induced syncope, to track arterial Carbon Dioxide saturation during prolonged apnea, or breath holding, performed prior to submaximal physical activity.

During this investigation, researchers tracked arterial Oxygen saturation using a beat-by-beat pulse oximeter, blood lactate concentration, and respiratory exchange ratio (RER) to track preferential macronutrient utilization following physical activity [8]. From the findings, researchers noted that the experienced divers had a far lower partial pressure of Carbon Dioxide and Oxygen in the blood following exercise when compared to control iterations [8]. Researchers postulated that, while there were significant differences in these metrics following exercise and hypoxic exposure relative to the controls, it was possible that the lack of familiarity with the above-water environment, may have yielded undue influence on the effects. Researchers suggested that future investigations implement cognitive assessments to be performed in both the hypoxic and control environments in this trained population to identify the potential deleterious effects of this environment on cognitive function [8].

Finally, in response to apnea exposure in certain divers, sympathetic activity can be ameliorated with the cessation of respiration, allowing certain individuals to remain underwater for extended periods of time [9]. Individuals whose training involves high stress environments and SCUBA insertion, such as the U.S. Army Special Forces Combat Divers and trainees at the Combat Diver Qualification Course (CDQC), train to optimize and utilize many physiological skills and adaptations [10]. This course is extremely rigorous both physically and mentally, placing a very high demand on cardiorespiratory function. Learning to optimize performance in the hypoxic environment through optimization of the dive response with repeated apneas is critical to both training and mission success. It is possible that enhancing these adaptations to hypoxia, can be learned and better allow individuals to sustain optimal neurocognitive function, which could be assessed using the ImPACT or KD test [10].

\section{References}

1. Notebaert AJ, Guskiewicz KM (2005) Current trends in athletic training practice for concussion assessment and management. Journal of Athletic Training 40(4): 320-325.

2. Wen XH, Li Y, Han D, Sun, L, Ren PX, et al. (2018) The relationship between cognitive function and arterial partial pressure 02 in patients with COPD: A meta-analysis. Medicine 97(4): 9599.

3. Schatz P (2010) Long-term test-retest reliability of baseline cognitive assessments using ImPACT. The American Journal of Sports Medicine 38(1): 47-53.

4. Tjarks BJ, Dorman JC, Valentine VD, Munce TA, Thompson PA, et al. (2013) Comparison and utility of King-Devick and ImPACT® composite scores in adolescent concussion patients. Journal of Neurological Science 334(1-2): 148-153.

5. Dziemianowicz MS, Kirschen MP, Pukenas BA, Laudano E, Balcer LJ, et al. (2012) Sports-related concussion testing. Current Neurology and Neuroscience Reports 12(5): 547-559.

6. Leong DF, Balcer LJ, Galetta SL, Liu Z, Master CL (2014) The KingDevick test as a concussion screening tool administered by sports parents. The Journal of Sports Medicine and Physical Fitness 54(1): 70-77.

7. Bartholomew CJ, Jensen W, Petros TV, Ferraro FR, Fire KM, et al. (1999) The effect of moderate levels of simulated altitude on sustained 
cognitive performance. The International Journal of Aviation Psychology 9(4): 351-359.

8. Lindholm P, Gennser M (2005) Aggravated hypoxia during breathholds after prolonged exercise. European Journal of Applied Physiology 93(5-6): 701-707.

9. Foster GE, Sheel AW (2005) The human diving response, its function, and its control. Scandinavian Journal of Medicine \& Science in Sports 15(1): 3-12.
10. Morgan CA, Cho T, Hazlett G, Coric V, Morgan J (2002) The impact of burnout on human physiology and on operational performance: A prospective study of soldiers enrolled in the combat diver qualification course. The Yale Journal of Biology and Medicine 75(4): 199-205.
Your next submission with Juniper Publishers will reach you the below assets

- Quality Editorial service

- Swift Peer Review

- Reprints availability

- E-prints Service

- Manuscript Podcast for convenient understanding

- Global attainment for your research

- Manuscript accessibility in different formats ( Pdf, E-pub, Full Text, Audio)

- Unceasing customer service

Track the below URL for one-step submission https://juniperpublishers.com/online-submission.php 